\title{
Uso de histórias em quadrinhos como recurso didático no ensino de Geografia: uma possibilidade para trabalhar a categoria Lugar
}

\author{
The use comics as a didactic resource in teaching Geography: a possibility to work \\ with the Place category
}

\author{
lan Moura Martins ${ }^{1}$ \\ Teresa Cristina Cantanhede Borges ${ }^{2}$ \\ Audivan Ribeiro Garces Junior ${ }^{3}$
}

\begin{abstract}
Resumo
O presente artigo fez uso das histórias em quadrinhos como um recurso didático objetivando uma aproximação teórica do estudo da categoria geográfica Lugar com a realidade dos alunos. Para traçar essa conexão, inicialmente foi feita uma revisão de literatura. A pesquisa participante consolidou a abordagem metodológica de intervenção em um contexto educacional. Os direcionamentos de Paulo Freire foram de suma importância para a concretização deste trabalho, no que tange a utilização de mecanismos que facilitem o processo de ensino-aprendizagem. Para o delineamento metodológico, foi feito em um primeiro momento, uma oficina no formato híbrido com os alunos sobre a concepção de Lugar para a Geografia assim como as histórias em quadrinhos (HQs) e um aplicativo que pudesse materializar a sua confecção. Após esse momento, os alunos construíram o recurso dando-lhe posteriormente um feed back sobre o uso das HQs, indicando que elas são mecanismos que ajudam no processo de ensinoaprendizagem. Entretanto, para adoção de qualquer recurso ou ferramenta faz-se necessário conhecer a realidade dos atores sociais a qual se deseja aplicar, para desta forma, traçar os melhores caminhos na busca de uma educação mais participativa, democrática, dinâmica e próxima de suas vivências.
\end{abstract}

Palavras-chave: Histórias em Quadrinhos. Lugar. Ensino-aprendizagem.

\begin{abstract}
The present article made use of comics as a didactic resource aiming at a theoretical approximation of the study of the geographic category Place with the students' reality. To make this connection, it initially conducted a literature review. Participant research

\footnotetext{
1 Graduando em Geografia/Licenciatura pela Universidade Federal do Maranhão. Técnico em Meio Ambiente pelo Instituto Federal do Maranhão. Professor da rede particular de ensino em São Luís/MA. Email: ianmoura.44@gmail.com

${ }^{2}$ Mestra em Saúde e Meio Ambiente pelo Programa de Pós-Graduação em Saúde e Ambiente. Graduada em Geografia Bacharelado e Licenciatura Plena pela Universidade Federal do Maranhão. Professora da rede particular de ensino em de São Luís/MA. E-mail: teresaccantanhedeog@gmail.com

3 Doutorando do Programa de Pós-graduação em Geografia da Universidade Federal do Ceará. Mestre em Saúde e Ambiente pelo Programa de Pós-Graduação em Saúde e Ambiente. Professor da rede pública municipal de São Luís/MA. E-mail: audivanribeiro@gmail.com
} 


\section{-Revista de Iniciação à Docência, v.6, n.2, 2021- \\ Publicação: dezembro, 2021 - ISSN 2525-4332}

consolidated the methodological approach of intervention in an educational context. The Paulo Freire's directions were of utmost importance for the realization of this work, regarding the use of mechanisms that facilitate the teaching-learning process. For the methodological design, in a first step, a workshop was held in hybrid format with the students on the conception of Place for Geography such as the comic strips (comics) and an application that could materialize their making. After this moment, the students built the resource by later giving feedback on the use of comics, indicating that they are mechanisms that help in the teaching-learning process. However, for the adoption of any resource or tool, it is necessary to know the reality of the social actors to which one wishes to apply, so that, in this way, we can trace the best paths in the search for a more participative, democratic, dynamic, and close to their experience's education.

Keywords: Comics. Place. Teaching-Learning.

\section{Introdução}

No Brasil, a inclusão das Tecnologias da Informação e Comunicação (TIC's) no ensino vem ocorrendo, sobretudo, a partir das últimas décadas do século XX, refletindose na "popularização" e o "barateamento" das ferramentas tecnológicas que possuem função didático-pedagógica. Algumas ferramentas tecnológicas foram paulatinamente se aperfeiçoando e incorporando aplicativos e programas que a priori não tenham sido pensados para a educação, a exemplo do Google Earth. Esse programa possibilita estudar transformações geo-históricas que ocorrem no espaço geográfico (MÂCEDO; SILVA; MELO, 2015).

Apesar do Google Earth possibilitar uma aprendizagem contextualizada, ela ainda é trabalhada em alguns contextos escolares de forma distanciada da realidade dos alunos, mostrando-se difícil para alguns ou menos interessante para outros. Frente a esse processo, é necessário entender a realidade social em que os alunos estão inseridos, assim como trabalhar sobre as diferentes formas de linguagem no Ensino de Geografia (MÂCEDO; SILVA; MELO, 2015).

De acordo com Cavalcanti (2002), essa multiplicidade na linguagem deve perpassar desde a linguagem verbal ao uso de figuras ilustrativas e instrumentos do meio de comunicação, podendo estabelecer a relação dos conteúdos geográficos com o conhecimento prévio dos alunos.

Dessa forma, os recursos didáticos são ferramentas importantes na construção do processo de ensino-aprendizagem, desde que se tenha conhecimento da situação da comunidade escolar da qual o sujeito faz parte, assim como os entraves e facilidades que estarão presentes na utilização dos recursos, uma vez que o trabalho educacional deve ser voltado para a responsabilidade social e política (FREIRE, 1967). 


\section{-Revista de Iniciação à Docência, v.6, n.2, 2021- \\ Publicação: dezembro, 2021 - ISSN 2525-4332}

Considerando o contexto anteriormente descrito, o presente trabalho fez uso das histórias em quadrinhos (HQs) como recurso didático que podem possibilitar o entendimento da categoria Lugar (enfatizando que essa categoria geográfica é de fácil assimilação da vivência do aluno com o conteúdo trabalhado em sala de aula). A escolha por este recurso didático deu-se pela facilidade de acesso dos alunos e por ser um recurso que adequada-se ao uso manual e/ou via aplicativo/programa, podendo ser aplicado no sistema de ensino híbrido.

O aplicativo utilizado na construção das Histórias em Quadrinhos é gratuito (considerando que mesmo em instituições particulares de ensino, os alunos têm realidades diferentes) e pode ser utilizado no setor público, que em alguns cenários ainda carecem de ações que viabilizem o processo de ensino-aprendizagem.

Conforme Alves (2017), as histórias em quadrinhos podem ser consideradas uma evolução das narrativas ilustradas que fizeram parte do processo de desenvolvimento da comunicação da espécie humana. Esse gênero textual é encontrado com facilidade em livros didáticos e sua inserção marca o momento da leitura ensinada (a partir de 1980), mas como recurso acessório, principalmente no ensino da Língua Portuguesa (RAMOS, 2015). Ressaltar- se que, em razão da versatilidade das HQs, o próprio Ministério da Educação (MEC) é favorável ao seu uso em sala de aula (DEFFUNE, 2010).

Partindo desses pressupostos, as HQs são percebidas no ensino contemporâneo como um estímulo aos estudantes, aguçando a curiosidade e desafiando seu senso crítico. De acordo com lanesko et al., (2017) a interligação do texto com a imagem, presente nas histórias em quadrinhos ampliam a compreensão de conceitos, ou seja, os quadrinhos proporcionam flexibilidade, expansão, articulação de ideias e formação de novos conceitos a partir de signos e instrumentos da linguagem (KAMEL; LA ROQUE, 2011).

Na compreensão de Vergueiro, Ramos (2009), as histórias em quadrinhos constroem realidades a partir das impressões do artista, haja vista que, os estereótipos ou ícones do cotidiano configuram interessantes elementos construtores de uma nova realidade. Gomes, Góis (2008) complementam esta ideia ao afirmarem que essa construção se aproxima do conhecimento geográfico por representar uma realidade centrada em ações no tempo e no espaço.

\section{Metodologia}

A pesquisa participante foi a abordagem que melhor orientou a construção do presente trabalho, haja vista, que um dos pesquisadores atua como docente na instituição onde foi realizada a prática pedagógica 4 com os alunos do sexto ano do Ensino

\footnotetext{
${ }^{4}$ Prática pedagógica é a união de teoria e prática no exercício de ensinar e apreender conhecimento, na ação pedagógica (SILVA, 2021).
} 


\section{-Revista de Iniciação à Docência, v.6, n.2, 2021- \\ Publicação: dezembro, 2021 - ISSN 2525-4332}

Fundamental. A pesquisa participante busca a participação do sujeito-pesquisador nas intervenções de problematizações construídas em sua pesquisa, observando não só as experiências e percepções dos diversos sujeitos envolvidos, mas, também os seus diálogos, comportamentos, vivências e o contexto em que estão inseridos (ITABORAHY, 2010).

Partindo desse entendimento, a pesquisa participante ajudou no delineamento dos procedimentos metodológicos que possibilitaram a análise dos resultados e discussão. Para fins elucidativos, os procedimentos estão organizados no fluxograma, conforme indicado na Figura 1:

Figura 1- Fluxograma dos Procedimentos Metodológicos

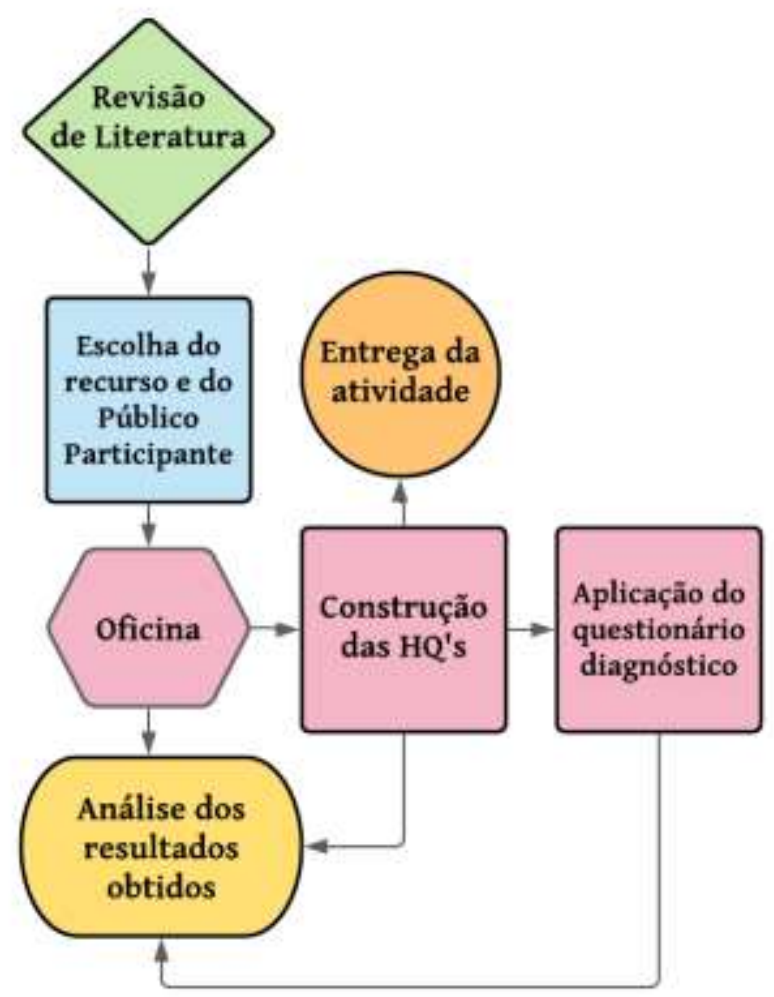

Fonte: dados da pesquisa, 2021.

O primeiro passo seguido foi a revisão de literatura em periódicos, dissertações, teses e livros sobre a categoria geográfica Lugar e como ela pode ser melhor trabalhada por intermédio das histórias em quadrinhos. Em razão da pandemia da COVID-19 e a temporária suspensão das aulas totalmente presenciais pelo Decreto $n^{\circ} 35.672$, de 19 de março de 2020 no Estado do Maranhão (MARANHÃO, 2020), a aplicação das histórias em quadrinhos aconteceu no formato híbrido, tendo em vista, que é o sistema utilizado na escola e HQs são um recurso que possibilitam a sua aplicação nesse formato de ensino. De acordo com CIEB (2020), o Ensino Híbrido é um formato de ensino que combina aulas presenciais e encontros virtuais que podem acontecer de forma simultânea ou não. 


\section{-Revista de Iniciação à Docência, v.6, n.2, 2021- \\ Publicação: dezembro, 2021 - ISSN 2525-4332}

Com base nessas informações, optou-se por utilizar o aplicativo StoryboardThat ${ }^{5}$, que é um conjunto de desenhos sequenciais para contar uma história, em outras palavras, é um organizador gráfico que planeja uma narrativa, por meio de uma direção linear das células, que ajudam na explicação de um processo e mostra a passagem do tempo (SHERMAN, 2021).

Antes de iniciar o emprego do recurso, foi solicitada a autorização a equipe gestora do colégio que aprovou a aplicação com os alunos do sexto ano do Ensino Fundamental. Ao todo participaram 31 alunos, sendo que um deles é diagnosticado com Transtorno do Espectro Autista (TEA). Apesar do número da amostragem ser quantitavamente pequena, ela atendeu qualitativamente a proposta que é o uso de recurso didático no ensino da Geografia com base no Lugar.

Após a autorização da equipe gestora, foi realizada na aula seguinte uma oficina por meio de uma apresentação em Power Point (os materiais utilizados foram: televisão não havia data show -, notebook, pincel para quadro branco e apagador) acerca da categoria geográfica Lugar e a HQs. Para que os alunos pudessem compreender teoricamente o que seria o lugar, o pesquisador por meio de suas leituras produziu um elemento gráfico, conforme pode- se verificar na Figura 2:

Figura 2- Concepções sobre o Lugar

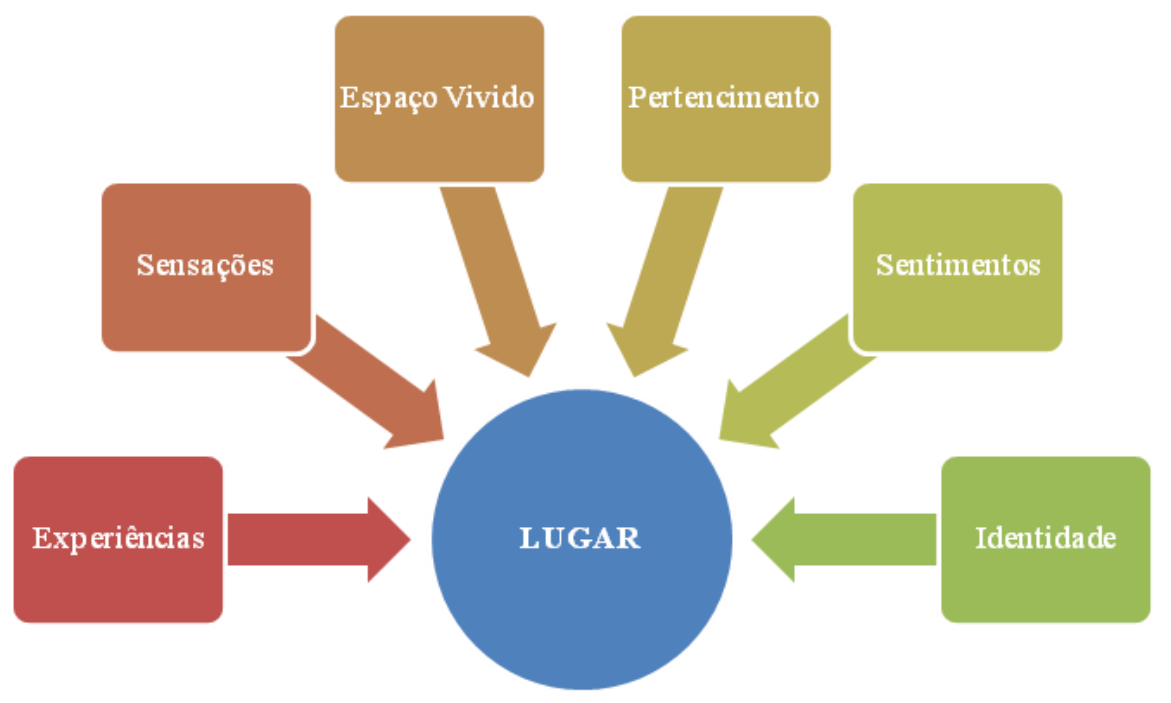

Fonte: Dados da pesquisa, 2021.

O Lugar é caracterizado pela identidade, pertencimento e construção social. Para auxiliar a associação da teoria com a percepção prática da categoria geográfica utilizou-se diferentes imagens, como mostra a Figura 3:

\footnotetext{
${ }^{5} \mathrm{O}$ Storyboardthat teve seu início como um aplicativo de desktop em 2012, criado por Aaron Sherman. 0 aplicativo recebeu o prêmio de Melhor Site de Ensino e Aprendizagem de 2015 pela American Association of School Librarians. Na versão gratuita o usuário pode criar uma história/narrativa de até seis células (SHERMAN, 2021).
} 
Figura 3- Representações sobre o Lugar

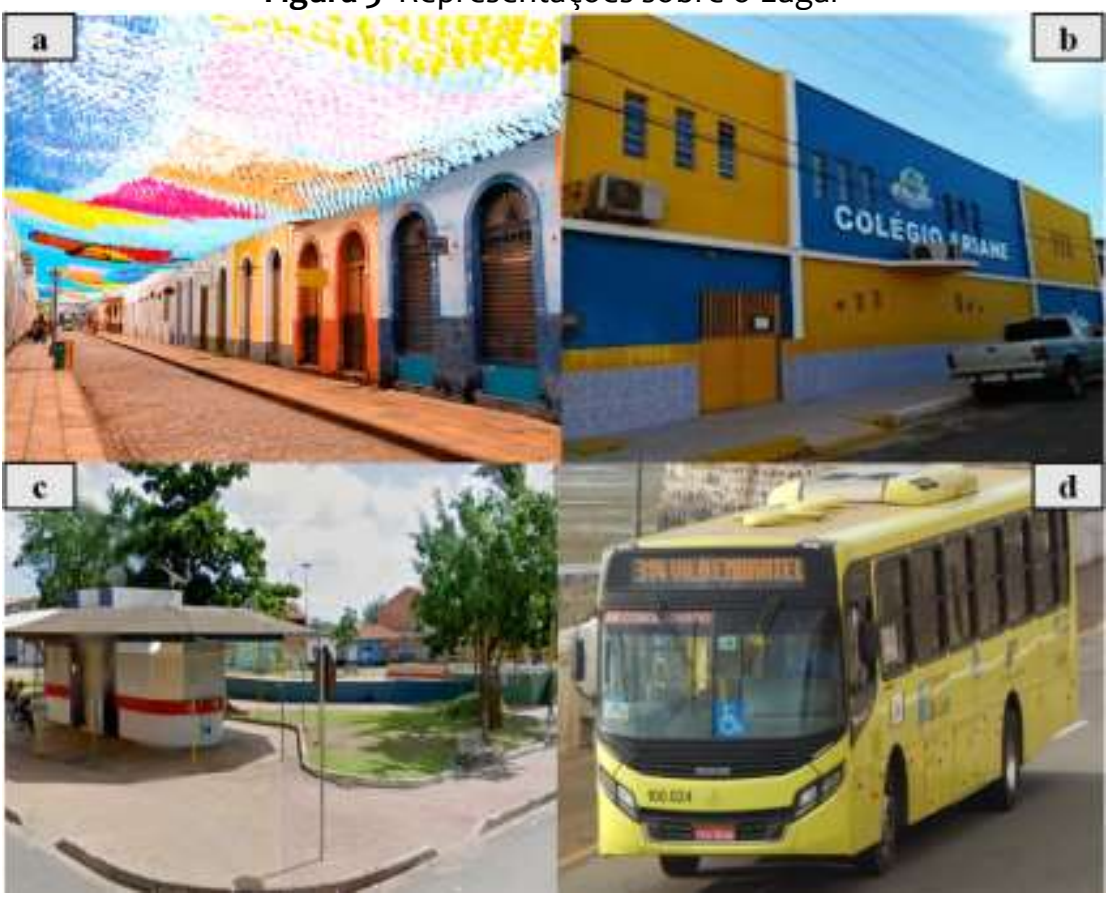

Fonte: Shutterstock, 2016 (Figura a); Norma, 2019 (Figura b); Garcia 2013 (Figura c); Sandro, 2018

(Figura d).

As imagens foram escolhidas intencionalmente para verificar a percepção dos alunos sobre o que era lugar. A Figura za foi escolhida, pois retrata o Centro Histórico de São Luís, onde é próximo geograficamente do bairro onde os alunos residem, além de ser um ponto turístico da cidade. A figura zb é a fachada da escola onde a pesquisa aconteceu, a figura $3 c$ é da praça das 7 palmeiras que fica próxima à escola e é famosa no bairro, e por fim, a figura 3d é do ônibus da linha Vila Embratel - Deodoro, já que muitos alunos relataram que não se sentem seguros nesse transporte público, ou seja, o ônibus seria um não lugar para os alunos ${ }^{6}$.

$\mathrm{Na}$ aula seguinte, os alunos iniciariam a produção das histórias em quadrinhos em sala de aula. Os alunos que estavam na turma virtual ou aqueles da turma presencial que possuíam aparelho celular com internet usaram o aplicativo StoryboardThat. A figura 4 mostra a sala de aula onde as aplicações aconteceram, assim como, a televisão utilizada para projeção da oficina:

\footnotetext{
${ }^{6}$ De acordo com Sá (2014, p. 211) "os "não lugares" permitem uma grande circulação de pessoas, coisas e imagens em um único espaço, por outro transformam o mundo em um espetáculo com o qual mantemos relações a partir das imagens, transformando-nos em espectadores de um lugar profundamente codificado, do qual ninguém faz verdadeiramente parte".
} 
Figura 4- Sala de aula e televisão utilizada

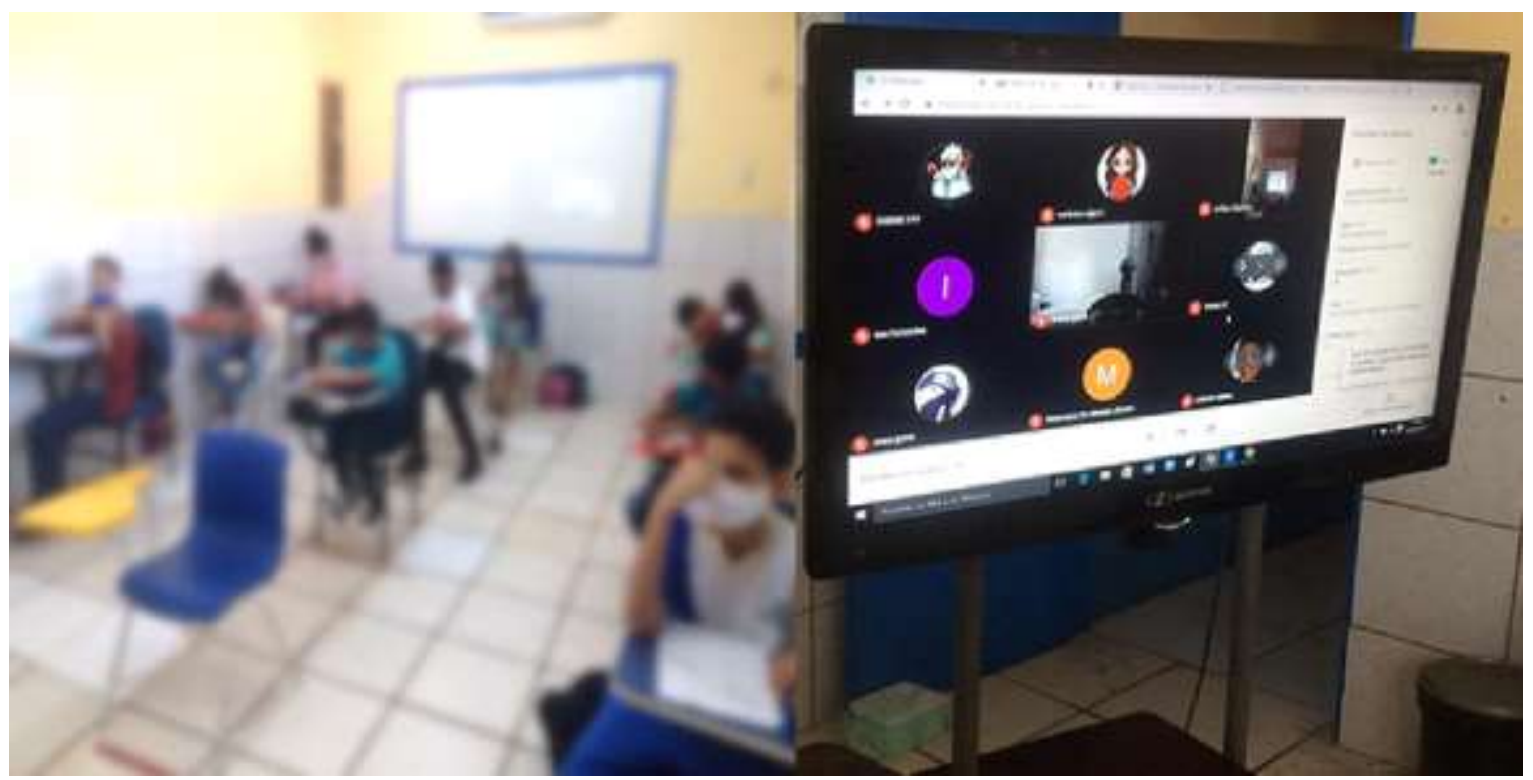

Fonte: Dados da pesquisa, 2021.

O aplicativo StoryboardThat foi apresentado para os alunos nos primeiros 20 minutos da aula no televisor da escola. Para aqueles que não tinham celular (turma presencial ou virtual), Ihes foi entregue um modelo em uma folha A4 elaborado pelos pesquisadores. Na folha havia 9 quadrados, onde cada quadrado representa uma célula. Todavia, aqueles que não conseguiam utilizar as ferramentas e que estavam na turma virtual, o fizeram de maneira manual, assim como os alunos da turma presencial.

Após construção das histórias em quadrinhos, os alunos foram orientados a fazer a devolutiva das atividades (aqueles que optaram por usar o aplicativo, enviaram a captura de tela - print - para o professor, o que acabou influenciando na qualidade das imagens). Posteriormente, foi aplicado um outro formulário (físico e digital) com os alunos para avaliar se eles conseguiram compreender o objetivo da aplicação. Aqueles que não puderam responder, foi lhes perguntado na aula seguinte o que acharam da atividade.

\section{Caracterização da comunidade escolar do Colégio Ariane}

O Colégio Ariane é uma instituição particular fundada em 02 de setembro de 1990. A instituição de ensino está localizada na rua 19, quadra 33, $n^{\circ} 4$ no bairro da Vila Embratel no sudoeste do município de São Luís capital do Estado do Maranhão (PPP- PROJETO POLÍTICO PEDAGÓGICO DO COLÉGIO ARIANE, 2018), conforme mostra espacialmente a Figura 5: 
Figura 5- Localização do Colégio Ariane

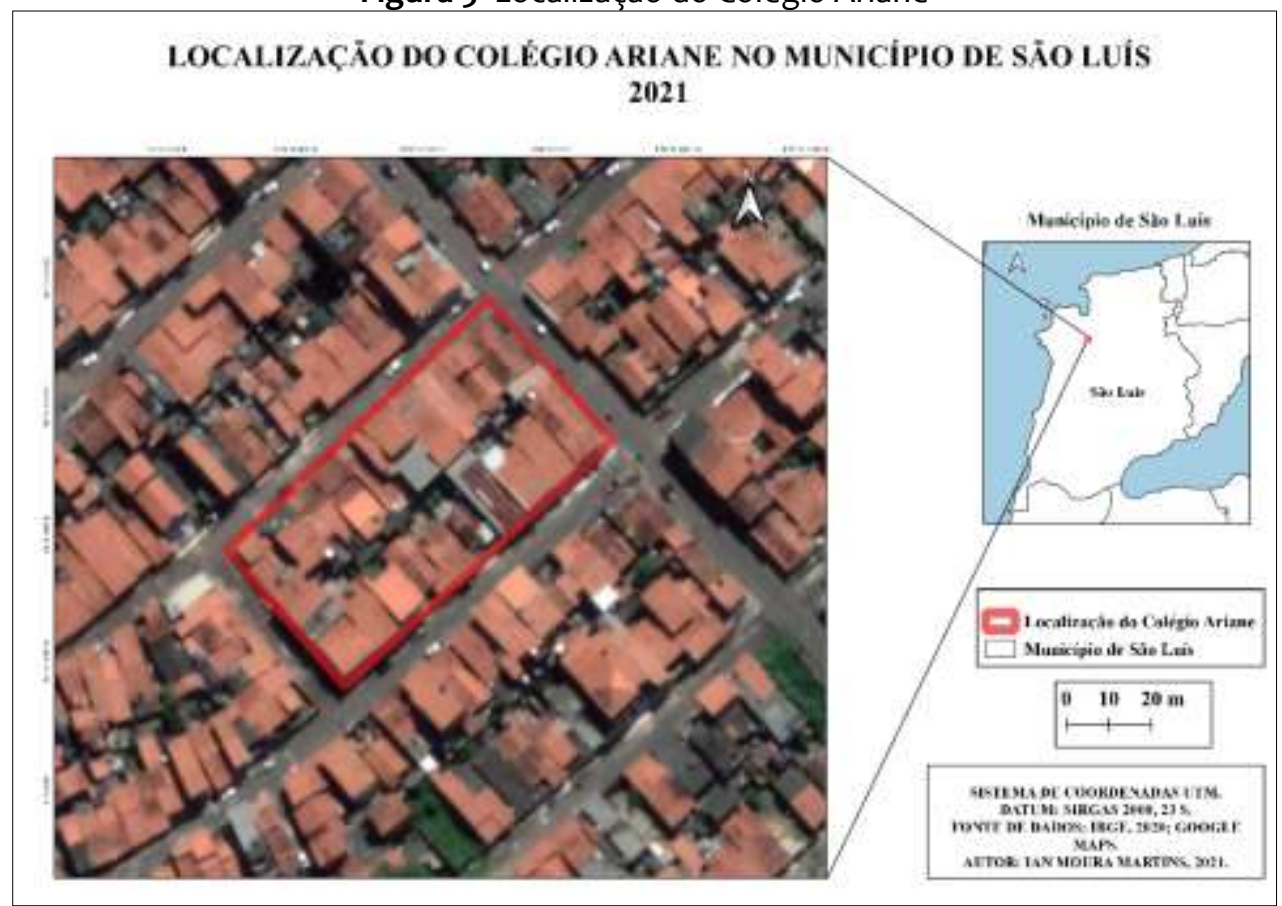

Fonte: Dados da pesquisa, 2021.

A instituição atende o Ensino Infantil, Ensino Fundamental I e II, sendo que no Fundamental II tem aulas das seguintes disciplinas: Artes, Língua Portuguesa, Língua Inglesa, Matemática, Educação Física, Ensino Religioso, Habilidade de Vida, Ciências e Geografia. O componente curricular, Geografia está descrito da seguinte forma:

Embora mantenha conceitos básicos de Geografia Física, Humana e Econômica, vem sofrendo constantes mudanças em relação ao conteúdo programático devido às alterações mundiais e à geopolítica que interpreta e tenta explicar os conflitos internacionais da atualidade. A cartografia é enfatizada em todos os anos $\left(6^{\circ}\right.$ ao $\left.9^{\circ}\right)$, uma vez que é essencial para o ensino da Geografia e tornou-se muito importante na educação contemporânea, tanto para as pessoas atenderem às necessidades do seu cotidiano quanto para estudarem o ambiente em que vivem (PPP- PROJETO POLÍTICO PEDAGÓGICO DO COLÉGIO ARIANE, 2018, p. 20).

A Geografia apresentada no PPP (2018) é uma Geografia básica. Apesar da tentativa de amplificação das discussões neste campo, percebe-se que a disciplina deveria contemplar outros aspectos, principalmente aqueles relacionados à vivência dos alunos e do bairro em que moram.

Porém, assim como outros bairros periféricos, foi criada uma representação estigmatizada do bairro associada principalmente a violência. A construção de uma imagem preconceituosa, revela a necessidade de ações que visem desconstruir esse tipo de imaginário pejorativo, tendo em vista, que a maioria dos alunos do colégio são residentes do bairro. Ressaltar-se que, esse desafio por mais difícil que seja, deve ser encarado pela Geografia e também pelos outros componentes curriculares, assim como pelos demais atores sociais envolvidos no processo de ensino-aprendizagem (MIRANDA, 2015). 


\section{O Lugar: um recorte epistemológico e conceitual}

Segundo Santos (2007), desde da antiguidade a humanidade busca identificar o lugar, seja como o lugar de proteção contra predadores, o lugar onde a caça e a coleta são boas etc. Após identificados, esses lugares eram marcados e nele deixavam-se sinais que permitissem ao ser humano retornar, "bem como estabelecer relação entre o lugar e a experiência vivida ali e traçar caminhos para diferentes lugares dá origem à necessidade de elaborar mapas e outras representações cartográficas", o lugar nesse contexto configurava-se como prática social e necessidade humana (AZEVEDO; OLANDA, 2018, p. 139).

O Lugar passa a ser estudada como categoria, na década de 1970, com a Geografia Humanista de base filosófica da Fenomenologia em que a categoria foi concebida para além do sentido de localização, passando a ser estudado como algo atrelado às subjetividades da experiência humana, ou seja, as individualidades de cada sujeito passam a ser evidenciadas (MENDES; PINOTTI, 2018). Nesse prisma, o lugar passa a estar relacionado as identidades e relações (em escalas diferentes). Dentre os teóricos da Geografia Humanística que elaboraram concepções sobre o Lugar, destacam-se os trabalhos de Yi-Fu-Tuan (1983).

Para Tuan (1983) o espaço pode transformar-se em lugar, na medida em que se atribui a ele valor e significação; o lugar não pode ser compreendido sem ser experienciado. Desta forma, o espaço torna-se um lugar a partir do momento em que o indivíduo consegue criar um laço de pertencimento e segurança. É no Lugar que se constrói a sensação de pertencimento, é nele que se obtém a estabilidade e segurança, ou seja, as experiências com o lugar podem trazer conforto ou desconforto, afetividade ou repulsa, atração ou negação. O pertencimento ao lugar também nomeado de topofilia, significa a ligação dotada de afetividade e pertencimento, sendo profunda e significativa (TUAN, 1980).

Essa somatória de experiências, sensações, sentimentos e subjetividades são características da categoria Lugar, que por sua vez, representam os aspectos históricos, culturais e sociais dos sujeitos em relação ao seu Lugar (MENDES; SOUSA; PEREIRA, 2017).

Para além da subjetividade e do pertencimento, o lugar ganha outra abordagem na Geografia Crítica com base no Materialismo Histórico Dialético, no qual o lugar passa a ser considerado como construção social (MOREIRA; HESPANHOL, 2007). Para Santos (1997), cada lugar é, à sua maneira, o mundo, e que a história concreta do nosso tempo, repõe a questão do lugar numa posição central.

Compreender o lugar é entender que ele está repleto de relações históricas e de vínculos afetivos. "Cada lugar geográfico concreto corresponde, em cada momento, um conjunto de técnicas e de instrumentos de trabalho, resultado de uma combinação 


\section{-Revista de Iniciação à Docência, v.6, n.2, 2021- \\ Publicação: dezembro, 2021 - ISSN 2525-4332}

específica que também é historicamente determinada", em outras palavras, os lugares são reflexos das complexidades sociais que acontecem no tempo-espaço, em uma relação dialética do global e do local, do novo e do velho (SANTOS, 1997, p. 46).

Moreira, Hespanhol (2007, p. 54) acrescentam que:

No lugar, o homem percebe o mundo através do corpo e do sentido, constitui então o espaço apropriável para viver. É necessário ser um espaço vivido, conhecido e reconhecido em toda a sua amplitude.

Nesse contexto, o lugar deve ser compreendido "enquanto um espaço vivido, construído nas relações sociais, abarca o cotidiano, a cooperação e as relações de conflito entre os indivíduos e o mundo" (MOREIRA; HESPANHOL, 2007, p. 57), isto é, o lugar é produto das relações humanas, no qual se explicita na construção de uma identidade e do sentimento de pertencimento.

\section{A Geografia escolar no Brasil: uma sucinta contextualização histórica}

De acordo com Silva, Corrêa (2014) a Geografia só passou a ser considerada como disciplina escolar no Brasil, em 1837 com a criação do Imperial Colégio Pedro II na cidade do Rio de Janeiro, tornando-se referência e parâmetro de currículo para o ensino em todo o país. Mas, o ensino era pautado em um caráter descritivo e abstrato. Os primeiros docentes eram pessoas conhecidas como de "notório saber", ou seja, eram pessoas oriundas de outras profissões, como advogados, engenheiros, médicos e seminaristas (PONTUSCHKA; PAGANELLI; CACETE, 2009).

Contrapondo-se a esse contexto, a adesão das produções de Delgado de Carvalho, nessa época, a citar a sua obra Metodologia de Ensino da Geografia publicada em 1925 foram responsáveis por um discurso mais moderno da Geografia Brasileira. Essas reflexões de Delgado de Carvalho foram facilitadas pela sua convivência com intelectuais europeus (franceses e ingleses), período em que se consolidou a Geografia Possibilista de Vidal de La Blache versus a Geografia Determinista alemã de Frederich Ratzel (MOREIRA, 2015).

É em meados do século XX que passam a ensinar de forma específica e separada, a Geografia e a História do Brasil. Cavalcanti (1998) afirma que, essa introdução da Geografia enquanto disciplina nesse período histórico, buscava a formação de cidadãos por intermédio da difusão da ideologia do nacionalismo patriótico (criar uma identidade nacional no Brasil).

Para Cassab (2009), a Geografia no Brasil só passou a ganhar uma nova dimensão, apenas na década de 1930, quando foi fundado o Curso Livre de Geografia na Universidade de São Paulo (1934) e na Universidade Federal do Rio de Janeiro (1938), (FÁVERO, 2006). A partir desse momento, é normatizado o ensino da disciplina no país e como reflexo desse processo surgem vários cursos de nível superior em Geografia nos anos seguintes, além da fundação de instituições importantes, como a Associação de 
Geógrafos Brasileiros (AGB) em 1935, o Instituto Brasileiro de Geografia e Estatística (IBGE) em 1936 e o Conselho Nacional de Geografia (CNG) no ano de 1937 (SILVA; CORRÊA, 2014).

Entre os anos de 1940 a 1970 passaram a serem publicados os primeiros livros didáticos de Geografia no Brasil. As primeiras publicações tinham influência das escolas francesas, mas, depois de 1980, houveram mudanças significativas na produção acadêmica de teses, dissertações, com mais foco na economia brasileira e na interação do espaço com a sociedade, além das críticas ao ensino decorativo pela Geografia Crítica (FELICIANO, 2017).

Com a chegada da corrente humanística, o enfoque passa a ser na realidade do aluno, focando no lugar. Em 1995 tem-se a criação dos Parâmetros Curriculares Nacionais (PCN's) que estabelecem alguns tipos de normas e regulamentações sobre o Ensino da Geografia Escolar, visando aproximar a disciplina do cotidiano dos alunos, de forma didática, orientados por eixos temáticos. A partir de 2018, os PCN's são oficialmente substituídos pela Base Nacional Comum Curricular (BNCC), (SILVA; CORRÊA, 2014).

De acordo com o Ministério da Educação (2018, p. 363), a" BNCC está organizada com base nos principais conceitos da Geografia contemporânea, diferenciados por níveis de complexidade". Pontuar-se que, apesar do espaço ser a categoria mais ampla e complexa da Geografia, é necessário que os alunos compreendam as demais categorias geográficas: Território, Região, Paisagem e Lugar (MOREIRA; HESPANHOL, 2007). Esta última categoria foi tomada como enfoque do presente trabalho.

\section{Construção das histórias em quadrinhos: facilidades e dificuldades}

De acordo com Deffune (2010, p. 159) "as HQs apresentam como essência a expressão de ideias, fatos ou acontecimentos, com abordagem crítica, satírica, cômica ou caricatural". Nesse sentido, para facilitar a leitura das histórias em quadrinhos, é necessário a priori, pensar em alguns elementos importantes, como o enredo da história, os personagens e se possível um título, tendo em vista, que nas HQs existem uma sucessão de quadrinhos (com ou sem balões) que possibilitam sintetizar a narrativa (DEFFUNE, 2010).

Pensar esses procedimentos foi um desafio lançado para os alunos, já que além de fazer a história eles deveriam pensar em um roteiro que contemplassem a categoria Lugar e sua compreensão, como se pode ver na Figura 6: 
Figura 6 - História em Quadrinhos “Indo a Cidade” (feito manualmente)

1) Monte uma história em quadrinhos

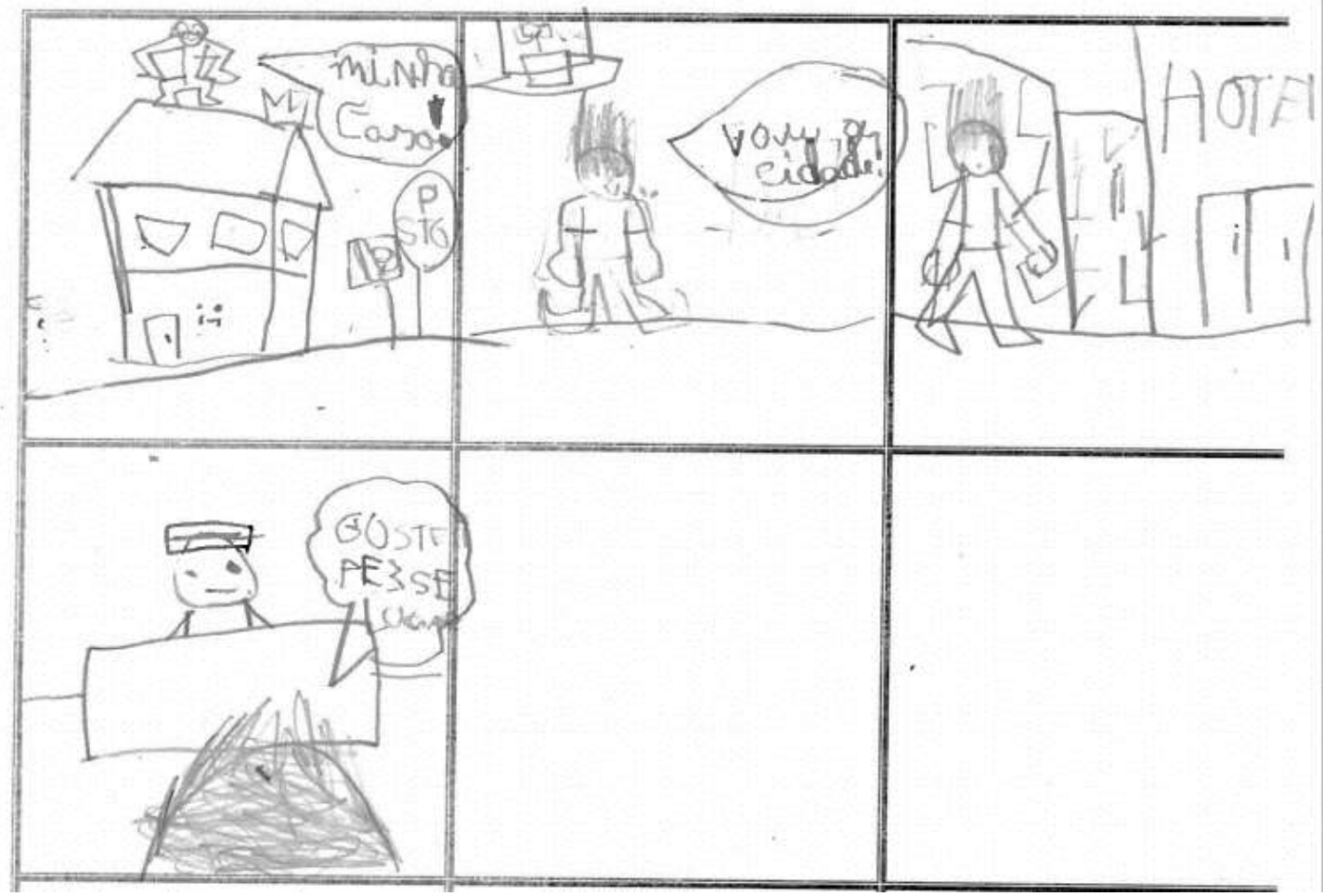

Fonte: Material produzido pelos alunos, 2021.

A história em quadrinho foi produzida pelo aluno com TEA. Com o título "indo à cidade", o enredo da sua história conta que ele está no telhado de sua casa (quadrado 1), depois resolve se deslocar de sua casa e ir à cidade (quadrado 2); ao chegar na cidade ele encontra um hotel (quadrado 3), após ver o hotel o personagem resolve entrar e ao fazer isso ele diz que gostou do hotel (quadrado 4). Já na figura 7: 
Figura 7- História em Quadrinhos "Passeando com a família” (feito manualmente)

1) Monte uma história em quadrinhos

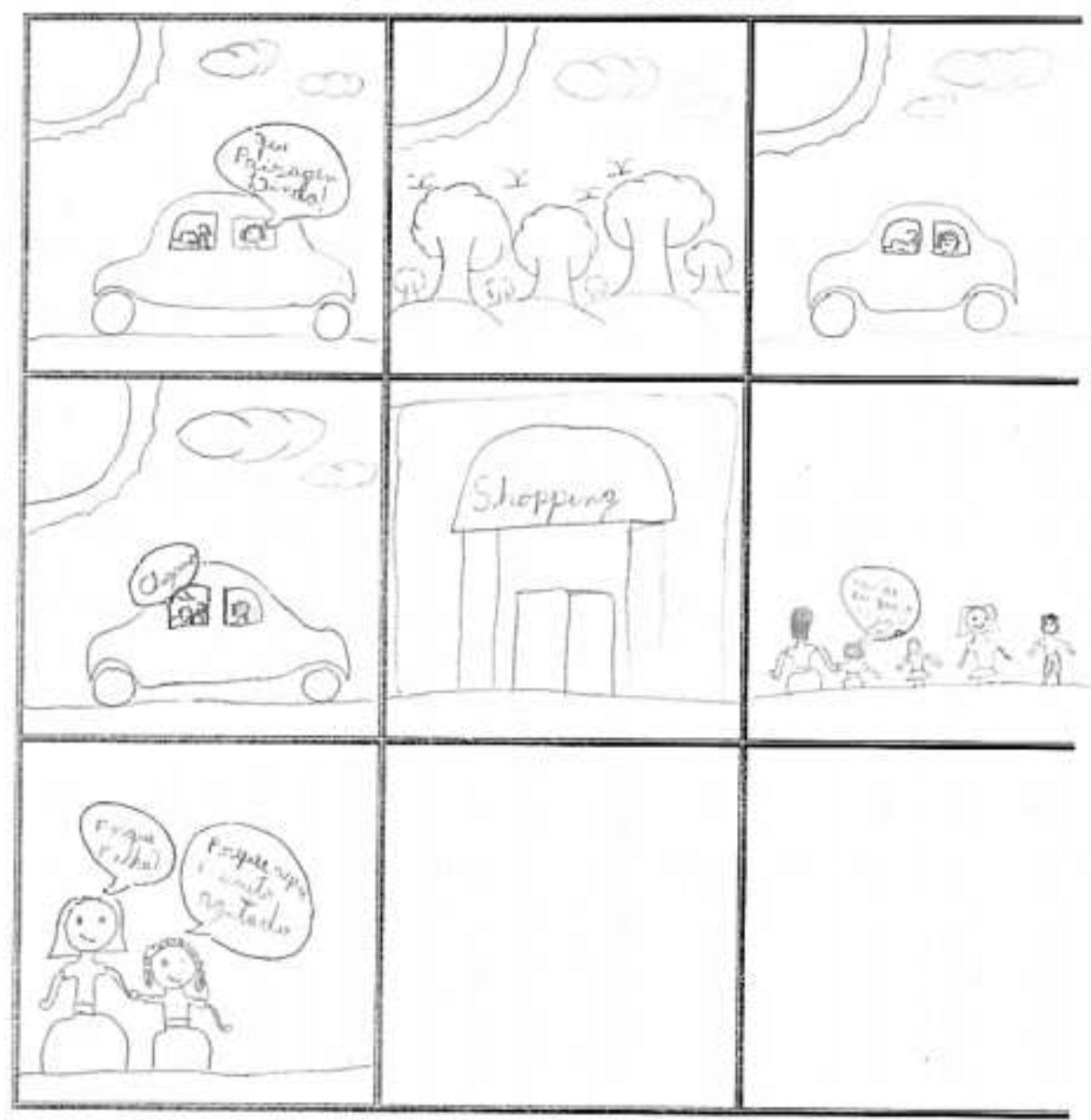

Fonte: Material produzido pelos alunos, 2021.

O aluno que fez a história em quadrinhos, utilizou 7 quadrados. No primeiro quadrado existem dois personagens em um carro e a personagem do banco de trás ao olhar pela janela diz que a paisagem é linda (quadrado 1), em seguida os personagens passam por uma floresta (quadrado 2) e depois voltam a estrada em um dia ensolarado (quadrado 3), após esse momento o personagem diz que chegou ao seu destino, (quadrado 4), que era o Shopping (quadrado 5), ao entrar no shopping o personagem diz para a sua mãe que quer ir embora (quadrado 6), a mãe pergunta o porquê e a personagem responde porque aqui é muito agitado (quadrado 7), demonstrando que ela não se sentiu bem lá. Além das histórias feitas manualmente, os alunos fizeram via aplicativo, como mostra a Figura 8: 
Figura 8- História em Quadrinhos “Indo na casa do tio” (elaborado no Storyboard That)
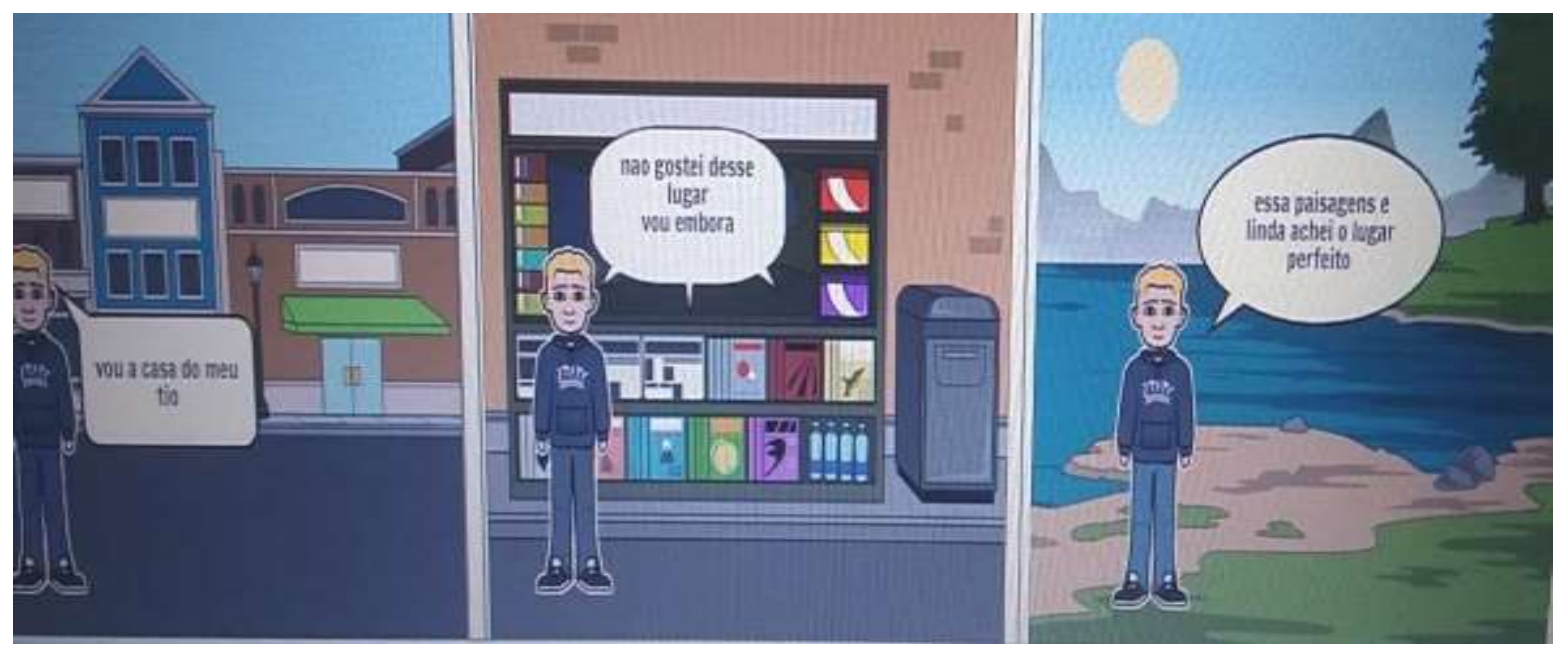

Fonte: Material produzido pelos alunos, 2021.

Para essa HQ foram utilizadas três células. A primeira tem-se um personagem que aparentemente está no centro urbano e diz que vai para casa do seu tio (quadrado 1), ao seu chegar na casa do seu tio, o personagem relata que não gostou da casa de seu tio (quadrado 2), então ele decide ir embora e vai para um ambiente com um lago e diz que a paisagem é linda e achou o lugar perfeito (quadrado 3). Na HQ da Figura 9, a pessoa que construiu também utilizou 3 células para montar o seu enredo com dois personagens:

Figura 9- História em Quadrinhos “Procurando a Igreja” (elaborado no Storyboard That)

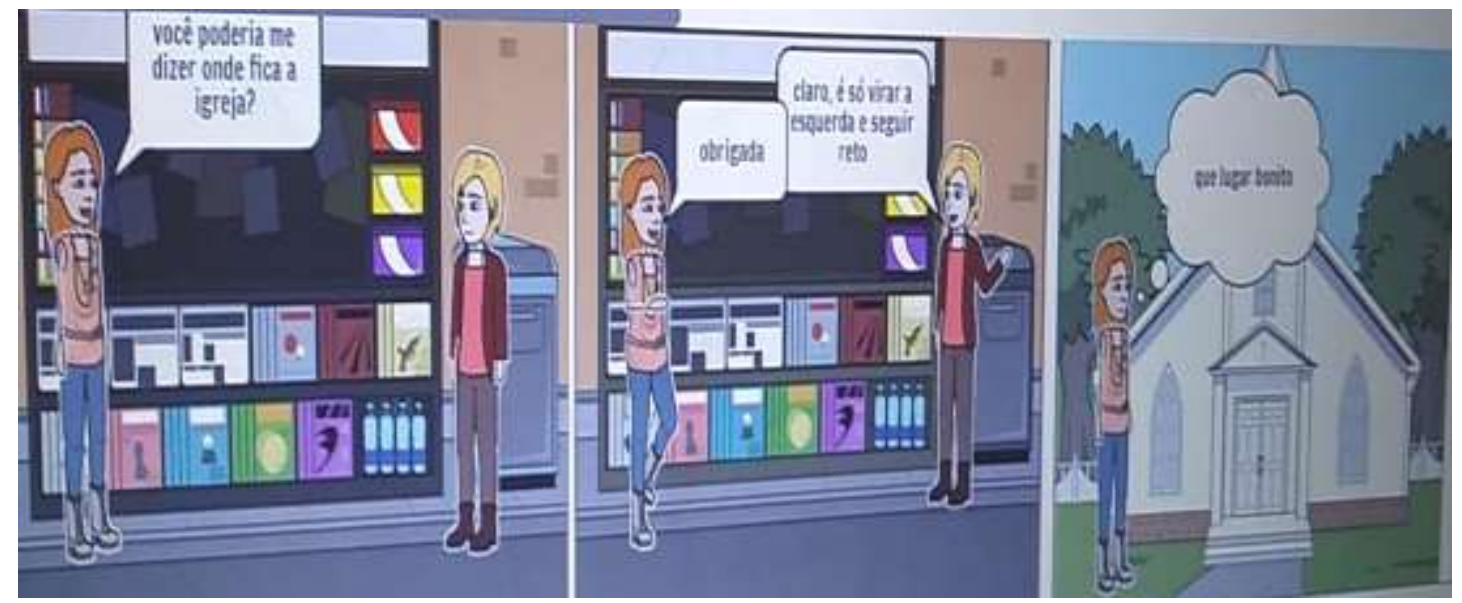

Fonte: Material produzido pelos alunos, 2021.

A personagem da esquerda pergunta para o personagem da direita, se ele poderia dizer onde fica a igreja (quadrado 1), o outro personagem da direita diz que claro e que era só virar à esquerda e seguir em frente (quadrado 2), a personagem da esquerda agradece, ao chegar na igreja ela diz que o lugar é bonito (quadrado 3). Em outras palavras, o aluno qualificou o ambiente como um lugar bonito. Depreende-se dessa HQ, que o aluno se sente bem e considera templos religiosos como lugar.

Depois da construção dos recursos, foi aplicado um formulário diagnóstico para compreender se os alunos entenderam o lugar e se foi dinâmico utilizar o recurso. Os 
alunos foram unânimes em dizer que gostaram de construir as histórias em quadrinhos, bem como conseguiram compreender o Lugar, consoante mostra a figura 10:

Figura 10- Nuvens de palavras acerca do entendimento dos alunos sobre o Lugar

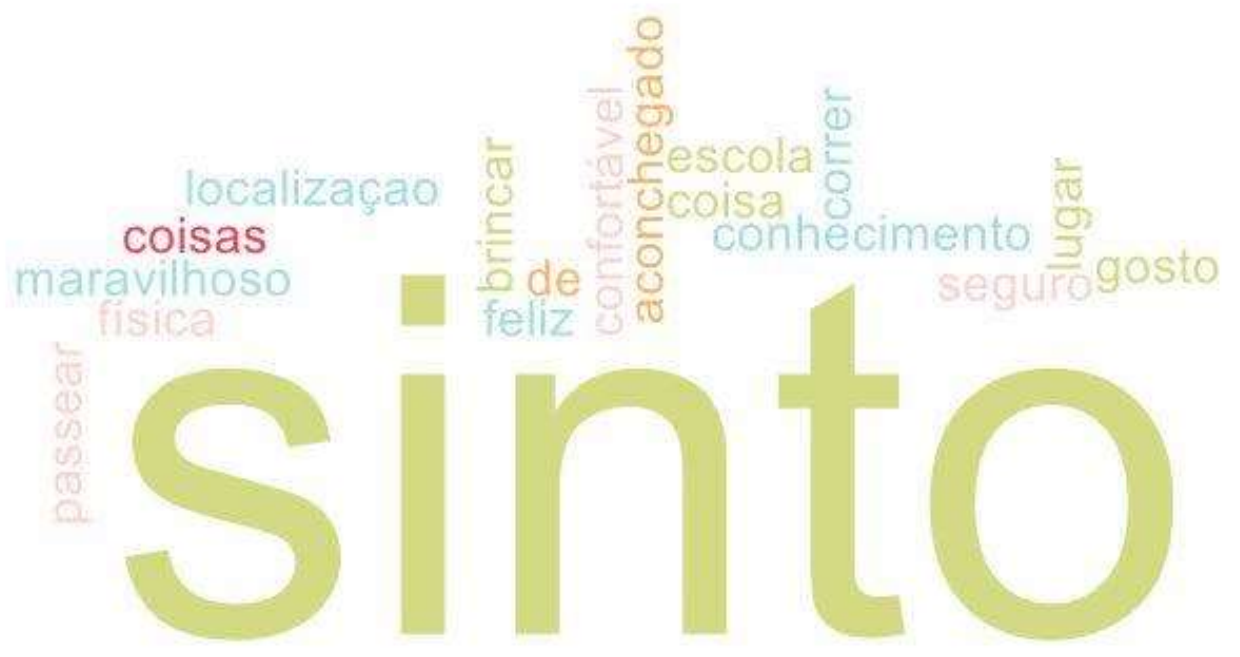

Fonte: Dados da pesquisa, 2021.

O feed back dado pelos alunos apontam que as histórias em quadrinhos ajudaram na compreensão da categoria geográfica Lugar, enquanto pertencimento, espaço vivido, sensações e experiências. Uma vez as HQs "facilitam o processo cognitivo dos estudantes apresentando relação com conteúdo da aula e sendo um material diferenciado e lúdico" (PAZ; RIBEIRO, 2017, p. 124).

Ainda segundo os alunos foi divertido construir o recurso, pois tornou a aula mais interessante, inclusive, eles indicaram que queriam que o professor promovesse outros momentos em que eles pudessem usar outros recursos ou ferramentas. Considerando ainda que, a "leitura dos quadrinhos desencadeia um processo duplo -leitura de textos e leitura de imagens de forma pluralizada, em que o único caminho pré-estabelecido é o das palavras" (DEFFUNE, 2010, p. 161).

Esse processo de leitura ajuda na construção de uma intepretação crítica dos alunos sobre a sua realidade e como eles materializaram a sua compreensão do lugar nas produções. Essa percepção crítica também foi observada no trabalho de Deffune (2010, p. 168), no qual das "cinco HQs, apenas duas abordam o espaço geográfico sob a perspectiva crítica".

\section{Considerações Finais}

A familiaridade com a tecnologia, acabou por ajudar a compreensão dos alunos acerca do Lugar, o que também foi facilitado pelo uso do aplicativo Storyboardthat, assim como a proposta da construção das HQs em que os alunos construíram histórias com um 
certo grau de informações e detalhes, apontando para o engajamento destes no ato da confecção.

As histórias em quadrinhos enquanto encaminhamento metodológico e pedagógico evidenciaram ser um mecanismo facilitador do processo de ensinoaprendizagem. Entretanto, o conhecimento da situação e dinâmica da comunidade escolar é imprescindível antes de qualquer aplicação.

Somam-se a esses fatos, o enfoque na categoria geográfica Lugar, pois ela permite fazer uma aproximação entre o conteúdo da sala de aula com o cotidiano do alunato. Por fim, utilizar recursos que diversifiquem a aula e que sejam construídos tomando com base as vivências dos alunos, é um dos passos necessários para a construção de uma educação mais dinâmica, democrática e crítica.

\section{Referências}

ALVES, B. F. Histórias em Quadrinhos e Formação de Professores: um relato de experiência na licenciatura em Pedagogia da UFRPE, 2017. IV Jornadas Internacionais de Histórias em Quadrinhos. Anais [...]. Escolas de Comunicações e Artes da USP, 2017. Disponível em:

http://www2.eca.usp.br/anaiszajornada/anais4asjornadas/q_e_letramentos/bruno_fernan des_alves.pdf. Acesso em: 12 dez. 2020.

AZEVEDO, M. O.; OLANDA, E. R. Ensino do lugar: reflexões sobre o conceito de lugar na Geografia. Revista Ateliê Geográfico - Goiânia-GO, v. 13, n. 3, dez/2018, p. 136 - 156.

CASSAB, C. Reflexões sobre o Ensino de Geografia. Revista Geografia: Ensino \& Pesquisa, Santa Maria, 2009, v. 13 n. 1, pp. 43-50.

CAVALCANTI, L. S. Geografia, escola e construção de conhecimentos. Campinas: Papirus, 1998.

CAVALCANTI, L. S. Geografia e práticas de ensino. Goiânia: Alternativa, 2002.

CENTRO DE INOVAÇÃO PARA A EDUCAÇÃO BRASILEIRA (CIEB). Discussões sobre a

Educação na Pandemia geram uma confusão de termos: entenda os diferentes conceitos, 2020. Disponível em: https://cieb.net.br/glossario/. Acesso em: 24 mar. 2021.

DEFFUNE, G. Relato de uma experiência de história em quadrinhos no ensino da Geografia. Revista Boletim de Geografia, v. 28, p. 157-169, 2010. Disponível em: http://periodicos.uem.br/ojs/index.php/BolGeogr/article/view/8628. Acesso em: 20 nov. 2021.

FÁVERO, M. L. A. A Universidade no Brasil: das origens à Reforma Universitária de 1968. Revista Educar, Curitiba, n. 28, p. 17-36, 2006. Editora UFPR. Disponível em: https://www.scielo.br/j/er/a/yCrwPPNGGSBxWJCmLSPfp8r/?format=pdf\&lang=pt. Acesso em: 06 dez. 2021.

FELICIANO, L. A. S. O Ensino de Geografia no Brasil: do Colégio Pedro II a Universidade de São Paulo- 1837 a 1934. XIII Congresso Nacional de Educação. Anais [...]. Pontifícia Universidade Católica do Paraná. Curitiba, 2017. Disponível em:

https://educere.bruc.com.br/arquivo/pdf2017/25271_12024.pdf. Acesso em: 09 mar. 2021. 
FREIRE, P. Educação Como Prática da Liberdade. Editora Paz e Terra. 1967

GOMES, P. C. C.; GÓIS, M. P. F. A cidade em quadrinhos: elementos para a análise da espacialidade nas histórias em quadrinhos. Revista Cidades, Presidente Prudente, v. 5, n. 7, jul/dez, 2008.

ITABORAHY, N. Z. Uma reflexão sobre a pesquisa participante em Geografia: lugares em construção, 2010. Disponível em: https://www.ufjf.br/nugea/files/2010/og/Umareflex\%C3\%A30-sobre-a-pesquisa-participante-em-Geografia.pdf. Acesso em: 03 fev. 2021.

KAMEL, C., LA ROCQUE, L. As histórias em quadrinhos como linguagem fomentadora de reflexões - uma análise de coleções de livros didáticos de ciências naturais do ensino fundamental. Revista Brasileira de Pesquisa em Educação em Ciências, 2011.

MÂCEDO, H. C.; SILVA, R. O.; MELO, J. A. B. O Uso das TIC'S na aprendizagem de conceitos cartográficos e geográficos no Ensino Fundamental. Revista de Ensino de Geografia, Uberlândia, v. 6, n. 10, p. 88-105, jan./jun. 2015.

MARANHÃO. Decreto $n^{\circ}$ 35.672, de 19 de março de 2020. Disponível em: https://www.ma.gov.br/agenciadenoticias/wp-content/uploads/2020/03/DECRETO35.672DE-19-DE-MAR\%C3\%87O-DE-2020.pdf. Acesso em: 20 fev. 2021.

MENDES, D. B; PINOTTI, B. R. O lugar como referência no ensino de Geografia: Contribuições do subprojeto “Fazendo Geografia por meio de projetos de trabalho" para a compreensão dos estudantes do ensino médio acerca de sua realidade local na cidade de Presidente Prudente -São Paulo. Revista GeoAtos. v. 1, n. 5, Presidente Prudente, 2017. MENDES, R. A.; SOUSA, E. S.; PEREIRA, A. J. A importância da categoria lugar no ensino de Geografia: um estudo de caso na Escola Estadual modelo em Araguaína - TO. Revista Tocantinense de Geografia, Araguaína (TO), Ano 06, n. 11, set/dez. 2017.

MINISTÉRIO DA EDUCAÇÃO. Base Nacional Comum Curricular (BNCC), 2018. Disponível em:http://basenacionalcomum.mec.gov.br/images/BNCC_EI_EF_110518_versaofinal_site.p df. Acesso em: 09 mar. 2021.

MIRANDA, P. P. B. Aonde você pensa que vai? Violência, medo e estigmas nas páginas dos jornais populares de São Luís - MA, 2015. XVIII Simpósio Nacional de História. Anais [...]. Florianópolis/ SC. Universidade de Santa Catarina, 2015. Disponível em: http://www.snh2015.anpuh.org/resources/anais/39/1439851095_ARQUIVO_AONDEVOCEP ENSAQUEVAl1.pdf. Acesso em: 01 abr. 2021.

MOREIRA, E. V.; HESPANHOL, R. A. M. O Lugar como uma construção social. Revista Formação, $\mathrm{n}^{\circ}$ 14, volume 2, 2017, p. 48-60.

MOREIRA, R. O Pensamento Geográfico Brasileiro. vol. 1. As matrizes clássicas

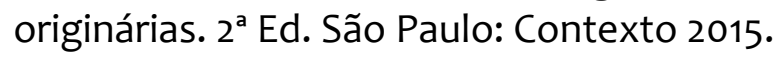

PAZ, O. L. S.; RIBEIRO, I. A. História em quadrinhos na análise geográfica do século XX: proposta de encaminhamento metodológico no ensino médio. Revista Cerrados. 15. 107, 2017. Disponível em:

https://www.researchgate.net/publication/321982863_Historia_em_quadrinhos_na_anali se_geografica_do_seculo_XX_proposta_de_encaminhamento_metodologico_no_ensino _medio. Acesso em: 20 nov. 2021. DOI: $10.22238 /$ rc24482692v15n22017p107a128.

PPP- PROJETO POLÍTICO PEDAGÓGICO do Colégio Ariane. São Luís/MA, 2018. 
PONTUSHKA, N. N.; PAGANELLI, T. I.; CACETE, N. H. Para ensinar e aprender Geografia. $3^{\text {a }}$ Ed. São Paulo. Ed. Cortez. 2009.

RAMOS, P. Histórias em Quadrinhos na Formação de Professores: uma discussão necessária. In: PEREIRA, S. e TOSCANO, M. (Eds.) $3^{\circ}$ Congresso Literacia, Media e Cidadania - Livro de Atas. Lisboa, CECS - Universidade do Minho: 2015.

ROCHA, G. O. R. A trajetória da disciplina Geografia no currículo escolar brasileiro (1837 1942). 1996. 300 f. Dissertação (Mestrado em Educação) - Pontifícia Universidade Católica de São Paulo, São Paulo, 1996.

SANTOS, D. O que é Geografia. Apostilado, 2007. Disponível em:

http://www.ebah.com.br/content/ABAAAfflwAD/que-geografia-douglas-santos. Acesso em: 13 abr. 2021.

SANTOS, M. A natureza do espaço: técnica e tempo, razão e emoção. 2. Ed. São Paulo: Hucitec, 1997.

SÁ, T. Lugares e não lugares em Marc Augé. Tempo Social, revista de sociologia da USP. v.26. n.2, 209-229. DOI: 10.1590/S0103-20702014000200012.

SHERMAN, A. O que é um Storyboard. Disponível em:

https://www.storyboardthat.com/pt/blog/e/o-que-\%C3\%A9-um-storyboard. Acesso em: 28 fev. 2021.

SILVA, E. C. O.; CORRÊA, G. D. Desafios e Perspectivas da Geografia Escolar do Século XXI, 2014. VII Congresso Brasileiro de Geógrafos. Anais [...]. Universidade Federal do Espírito Santo: Vitória, 2014. Disponível em:

http://www.cbg2014.agb.org.br/resources/anais/1/1404430936_ARQUIVO_Osdesafiosepe rspectivasdageografiaescolarnoseculoxxi.pdf. Acesso em: 09 mar. 2021.

SILVA, P. A. Prática pedagógica dos docentes. Revista Científica Multidisciplinar Núcleo do Conhecimento, ano 06, ed. 02, vol. 06, 2021, pp. 117-125. Fevereiro de. Disponível em: https://www.nucleodoconhecimento.com.br/educacao/pedagogica-dos-docentes. Acesso em: 29 nov. 2021. DOI:

10.32749/nucleodoconhecimento.com.br/educacao/pedagogica-dos-docentes.

TUAN, Yi Fu. Espaço e Lugar: a perspectiva da experiência. Trad. Lívia de Oliveira. São Paulo: Difel, 1983.

TUAN, Yi Fu. Topofilia: um estudo da percepção, atitudes e valores do meio ambiente. Trad. Lívia de oliveira. DIFEL: São Paulo, Rio de Janeiro, 1980.

VERGUEIRO, W.; RAMOS, P. Os quadrinhos (oficialmente) na escola: dos PCN ao PNBE. In: W. Vergueiro; P. Ramos (Orgs), Quadrinhos na educação: da rejeição à prática. (pp.9-42). São Paulo: Contexto, 2009.

VIEGAS, C. G. História da Educação. 1. ed. São Paulo: Ática, 2007, 328 p. 